\title{
Green synthesis and characterization of silver nanoparticles using leaves extract of Neem (Azadirachta indica L.) and assessment of its in vitro antioxidant and antibacterial activity
}

\author{
Naba Jyoti Deka $*$ Rita Nath*, Shantanu Tamuly*, Mousumi Hazorika*, Seema Rani Pegu** and Surjit Moni Deka*** \\ Department of Veterinary Biochemistry, College of Veterinary Science, Assam Agricultural University, Guwahati-781022, Assam, India \\ **Animal Health Division, National Research Centre on Pig, Indian Council of Agriculture Research, Rani-781131, Assam, India \\ ***Department of Biochemistry and Agricultural Chemistry, Assam Agricultural University, Jorhat-785013, Assam, India
}

\section{Article Info}

Article history

Received 12 March 2021

Revised 28 April 2021

Accepted 30 April 2021

Published online 30 June 2021

\section{Keywords}

Azadirachta indica $\mathrm{L}$.

Silver nanoparticles

SEM

TEM

Antioxidant

Antibacterial

\begin{abstract}
There is an increased demand for environment friendly non-toxic synthetic biological protocol for the synthesis of nanoparticles. The investigation was aimed to synthesize silver nanoparticles using leaves extract of Neem (Azadirachta indica L.), its characterization and assessment of in vitro antioxidant and antibacterial activity. Aqueous extract of the plant was used and synthesis of nanoparticles are confirmed by the colour change, followed by UV-Vis spectro photo meter analysis. The zeta potential measurement of the nanoparticles are found to be $-48.9 \mathrm{mV}$ and found stable. The synthesized nanoparticles are almost spherical in shape in SEM micrograph. In TEM analysis, the average size of the nanoparticles was found to be $38.54 \pm 2.94 \mathrm{~nm}$. It may be concluded that the leaves extract of the plant is found suitable for synthesis of silver nanoparticles, showed sensitive response against both grampositive (Staphylococcus aureus) and gram-negative bacteria (Escherichia coli). The antioxidant activity of the nanoparticles was also found higher than the extract alone.
\end{abstract}

\section{Introduction}

There has been a tremendous developments in nanotechnology and nanoscience which results in the establishment of several new fields for research. Nanoparticles can be synthesized by various methods like physical, chemical and biological method. The physical approaches include evaporation, condensation and laser ablation. Different metal nanoparticles such as silver, gold, lead sulfide, cadmium sulfide, and fullerene have been synthesized previously using the evaporation-condensation process. The absence of solvent contamination in the prepared thin films and the uniformity of nanoparticles distribution are the advantages of physical approaches in comparison with chemical processes (Kruis and Rellinghaus, 2000; Magnusson et al., 1999). The most common approach for synthesis of silver nanoparticles is chemical reduction by organic and inorganic reducing agents. Usually, various reducing agents, viz., sodium citrate, ascorbic acid, sodium borohydride, $\mathrm{N}$-dimethyl formamide (DMF) are used to reduce silver ions $(\mathrm{Ag}+)$ in aqueous or non-aqueous solutions and lead to the formation of metallic silver (Ag0) which is followed by agglomeration into oligomeric clusters. These clusters ultimately form the metallic colloidal silver particles (Wiley et al., 2005; Merga et al., 2007; Evanoff et al., 2004). However, these production methods are usually expensive,

Corresponding author: Mr. Naba Jyoti Deka

Department of Veterinary Biochemistry, College of Veterinary Science, Assam Agricultural University, Guwahati-781022, Assam, India E-mail: nabajyotiacademic@gmail.com Tel.: +91-7002834923

Copyright (C) 2021 Ukaaz Publications. All rights reserved.

Email: ukaaz@yahoo.com; Website: www.ukaazpublications.com labour intensive and potentially hazardous to the environment and living organisms. Therefore, there is an increased demand for environment friendly non-toxic synthetic protocol for the synthesis of nanoparticles which has increased interest towards biological approach.

Biological methods can be employed to synthesize silver nanoparticles without the use of any harsh, toxic and expensive chemical substances. The development of this efficient and green chemistry method employing natural reducing, capping, and stabilizing agents to prepare silver nanoparticles with desired morphology and size have become a major focus of researchers. Biological method is a green approach as bioreduction of metal ions are occurred by combinations of biomolecules found in extracts of certain organisms, e.g., enzymes, proteins, amino acids, polysaccharides, and vitamins. Many studies have reported successful synthesis of silver nanoparticle using microorganisms and biological system like plants (Ahmed et al., 2003; Ankamwar et al., 2005; Korbekandi et al., 2009 ; Iravani, 2011).

The significant advantage of using plant extracts for synthesis of silver nanoparticle is that plants are easily available, economic, safe, no use of any toxic chemical and have a large variety of metabolites that are involved in the reduction of silver ions. This synthetic protocol is quicker than the microbes in regard of synthesis. The main mechanism is based on plant mediated reduction due to phytochemicals. It was mentioned that the phytochemicals are involved directly in the reduction of the ions and formation of silver nanoparticles (Panigrahi, 2013). Plant mediated synthesis of nanoparticles was a green chemistry approach that connects technology with plants. 
The use of various types of medicinal plants has been increased by traditional medical practitioners for the treatments of different kind of diseases in India. One most common and largely used plant, Neem (A. indica) has tremendous medicinal properties such as anticancer, antimicrobial, cardioprotective, antidiabetic, analgesic, antispasmodic, antiemetic, hepatoprotective. It has been used by the rural people of Indian subcontinent since long years back. Since very little work has been done on green synthesis of silver nanoparticles, the present study was undertaken to synthesize silver nanoparticles using Neem leaf extracts followed by its characterization and assessment of in vitro antioxidant and antibacterial activity.

\section{Materials and Methods}

\subsection{Preparation of $A$. indica aqueous leaf extract}

The leaves of $A$. indica were collected from different parts of Guwahati, Assam, washed gently with distilled water, subjected to shade drying, pulverized in a grinder and stored in an air tight container till further processing. Two fifty grams of the powdered leaves were dissolved in $700 \mathrm{ml}$ of double distilled water and kept for a period of 3 days for maximum extraction with intermittent stirring on each day. At the end of 3rd day, the contents were filtered using muslin cloth followed by Whatman No.1 filter paper. The filtrate was collected and subjected to lyophilization (Freezone 2.5) to obtain semisolid consistency and kept in a refrigerator for further experiments.

\subsection{Green synthesis of nanoparticles}

Ten $\mathrm{ml}$ of refrigerated aqueous extract of A. indica were treated with $90 \mathrm{ml}$ of $1 \mathrm{mM} \mathrm{AgNO}_{3}$ solution. The resulting solution was mixed and incubated in dark to minimize the photo activation of $\mathrm{AgNO}_{3}$ at $37^{\circ} \mathrm{C}$ for overnight under static condition. There was change of colour of the solution from pale greenish (Neem) to dark black. It indicated the formation of plant mediated silver nanoparticle. The coloured solution was then centrifuged at 10,000 rpm for $10 \mathrm{~min}$, the supernatant liquid was discarded. The resulting suspension was redispersed in $10 \mathrm{ml}$ sterile distilled water and then centrifugation process was repeated for three times. After completion of the last centrifugation followed by supernatant discard, there was pellet formed at the bottom of the tube. Thereafter, the pellet was used for characterization of the synthesized nanoparticle.

\subsection{Characterization}

The biosynthesis of the plant mediated silver nanoparticles was preliminary monitored with the help of UV-Vis Spectrophoto meter (Systronics 106) in between the wavelength of $300-500 \mathrm{~nm}$ range. The distilled water was used as a blank. The dynamic light scattering analysis are carried out by a computer controlled particle size analyzer (Zetasizer, Nano ZS 90). The method was based on the laser diffraction method with multiple scattering techniques to study the size distribution of the nanoparticles in liquid dispersion. The surface charge of the nanoparticles was determined. It was essential for assessing the stability of the nanoparticles in aqueous solution. It was determined with the help of Zetasizer (Nano ZS 90). Scanning electronic microscopy analysis (Model: Carl Zeiss Sigma VP) was studied to know the shape of the synthesized nanoparticles. Thin films of the samples were prepared on a carbon coated copper grid by just dropping a very small amount of the sample on the grid, extra solution was brought out by a blotting paper and then the prepared film were put to dry a mercury lamp for $5 \mathrm{~min}$. Transmission electron microscope (Model: JEM-100 CX II) was used to directly view the nanoparticles and for direct measurement of the nanoparticles. The images were viewed over a fluorescent screen and recorded on a photographic film or a high resolution CCD camera. The clear observed microscopic views of the nanoparticles were documented in different range of magnifications. Transmission electron microscope (Model: JEM-100 CX II) was used to directly view the nanoparticles and for direct measurement of the nanoparticles. The images were viewed over a fluorescent screen and recorded on a photographic film or a high resolution CCD camera. The clear observed microscopic views of the nanoparticles aredocumented in different range of magnifications.

\subsection{Antibacterial evaluation}

The antibacterial activity of the plant mediated nanoparticle was evaluated against both gram-positive (Staphylococcus aureus) and gram-negative bacteria (Escherichia coli) by disc diffusion method of Bauer et al. (1966). The pathogenic microorganism are collected, screened and sub-cultured from the repository of Department of Veterinary Microbiology, College of Veterinary Science, Assam Agricultural University, Khanapara, Guwahati, Assam. The density of the bacterial cultures are diluted and adjusted to meet the Mc Farland standard, having a bacterial density of $1.5 \times 10^{8} \mathrm{cfu} / \mathrm{ml}$. Sterile nutrient agar plates were prepared and $24 \mathrm{~h}$ broth bacterial cultures are poured on the solidified plate. Surplus suspension was removed by rotating against the side of the plate. It was then allowed to dry for $10 \mathrm{~min}$. Sterile discs of diameter $10 \mathrm{~mm}$ were soaked in the nanoparticle suspension and these loaded discs were placed carefully on the surface of the medium, gently pressed downwards for proper contact and left for $30 \mathrm{~min}$ at room temperature for diffusion. For standards, discs of ampicillin $(10 \mathrm{mcg})$, ciprofloxacin ( $5 \mathrm{mcg}$ ), chloramphenicol $(30 \mathrm{mcg})$ were used. The plates were incubated for $24 \mathrm{~h}$ at $37^{\circ} \mathrm{C}$ and the zone of inhibition was observedand recorded in millimeters.

\subsection{Assessment of in vitro antioxidant activity}

For antioxidant assay, DPPH radical scavenging activity was evaluated as per the method of Cotelle et al. (1996) with some modification. DPPH radical reacts with antioxidants compounds that can donate hydrogen and gets reduced. DPPH when acted upon by an antioxidant was converted into diphenyl-picryl hydrazine. Three $\mathrm{ml}$ reaction mixture containing $200 \mu \mathrm{l}$ of DPPH $(100 \mu \mathrm{M})$ in methanol and $2.8 \mathrm{ml}$ of sample at various concentrations, viz., 50 $\mu \mathrm{g} / \mathrm{ml}, 80 \mu \mathrm{g} / \mathrm{ml}$ and $110 \mu \mathrm{g} / \mathrm{ml}$ in methanol was incubated at $37^{\circ} \mathrm{C}$ for $30 \mathrm{~min}$ and absorbance of test mixture was read at $517 \mathrm{~nm}$ using UV-Vis spectrophotometer. Butylated hydroxytoluene (BHT) was used as control in the same concentration range as the sample. The percentage inhibition of DPPH radical was calculated by comparing the result of the test with those of the control using the following formula:

$$
\% \text { inhibition }=\frac{\text { Absorbance of control }- \text { absorbance of test }}{\text { Absorbance of control }} \times 100
$$

\subsection{Statistical analysis}

The values were expressed as Mean \pm SE. The layout of experiment was randomized control trial (RCT) where IBM SPSS 20 and jmp 10 of SAS software was used to analyze data. 


\section{Results}

\subsection{UV-Vis Spectrophotometry analysis}

The formation of silver nanoparticle using leaves extract of $A$. indica was initially observed by the colour change (Figure 1), followed by UV-Vis spectrophotometry. The nanoparticles showed maximum absorbance in the range of 300-500 $\mathrm{nm}$ wavelength.

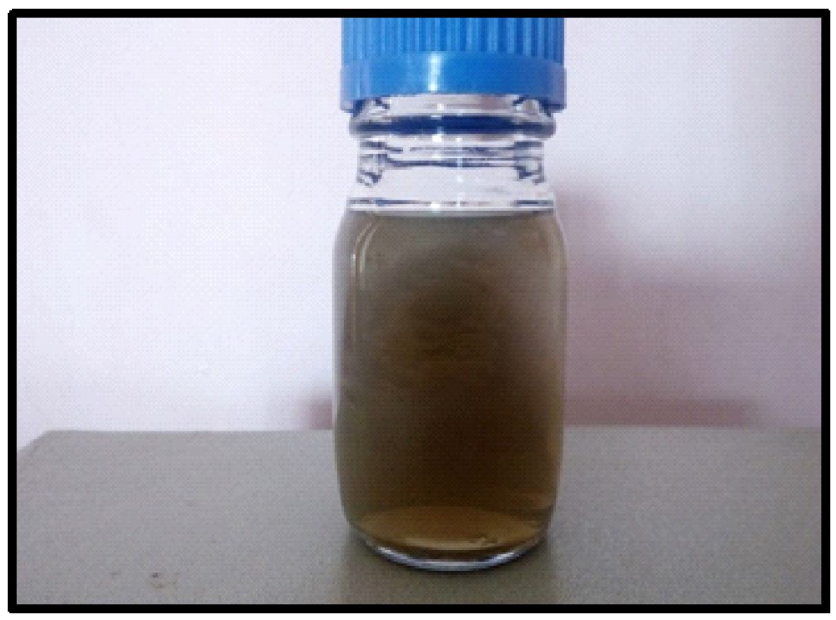

Figure 1: Colour of the reaction mixture after $24 \mathrm{~h}$ of incubation.

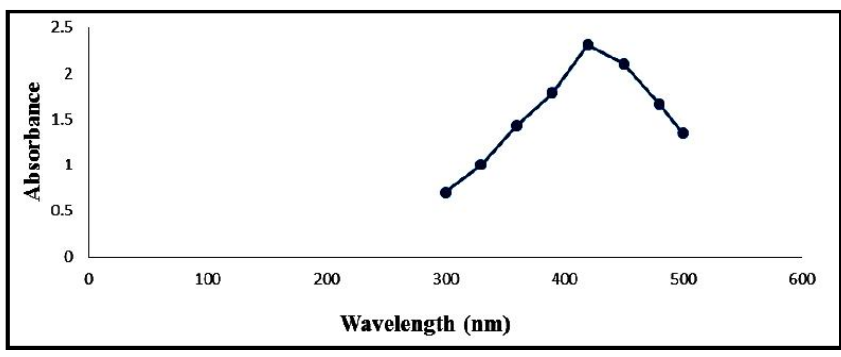

Figure 2: Absorbance spectra of synthesized nanoparticles between 300-500 $\mathrm{nm}$.

\subsection{Dynamic light scattering (DLS)}

The particle size distribution (PSD) of silver nanoparticle using Neem leaf extracts are shown in the Figure 3. The colloidal solution of synthesized silver nanoparticles derived from Neem leaf extract contain particles of different sizes with average size $384 \pm 0.57$ nm.

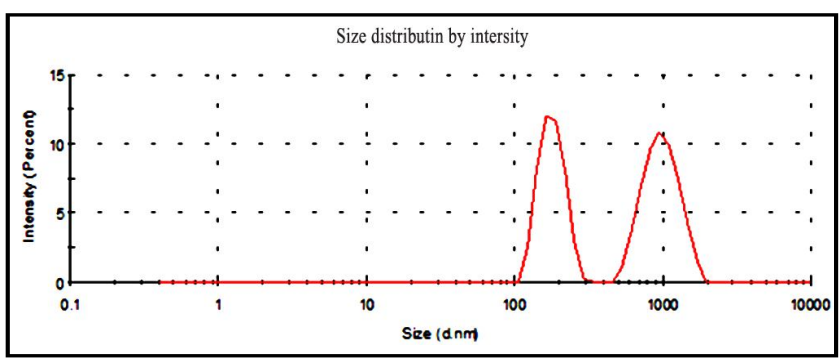

Figure 3: PSD of synthesized silver nanoparticles.

3.3 Zeta potential studies

The zeta potential of silver nanoparticles of Neem mediated AgNPs are found to be $-48.9 \mathrm{mV}$ and presented in Figure 4 . The nanoparti- cles in aqueous solution tend to aggregate into the large size macroparticles. The aggregation depends on the charge on the surface of the nanoparticles. The zeta potential analysis is a technique to determine the surface charge of nanoparticles. Due to charge of nanoparticles, there is formation of a double layer of oppositely charged ions on the surface of the nanoparticles which gives rise to the potential difference. It helps to know the stability of the synthesized nanoparticles. Zeta potential (surface potential) has direct relation with the stability of a form/structure as mentioned in Table1 (Panigrahi, 2013).

Table 1: Stability of the nanoparticles according to the potential charge

\begin{tabular}{|c|l|}
\hline Zeta potential $(\mathbf{m V})$ & Stability behavior of the colloid \\
\hline 0 to \pm 5 & Rapid coagulation or flocculation \\
\pm 10 to \pm 30 & Incipient instability \\
\pm 30 to \pm 40 & Moderate stability \\
\pm 40 to \pm 60 & Good stability \\
more than \pm 61 & Excellent stability \\
\hline
\end{tabular}

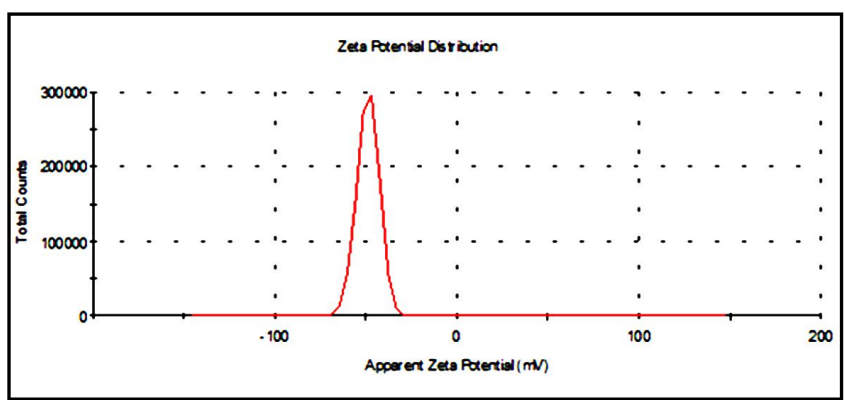

Figure 4: Zeta potential of synthesized silver nanoparticles. 3.4 Scanning Electron Microscopy (SEM)

The SEM micrographs of the synthesized nanoparticles are depicted in Figure 5. SEM provided further insight into the morphology of the silver nanoparticles.

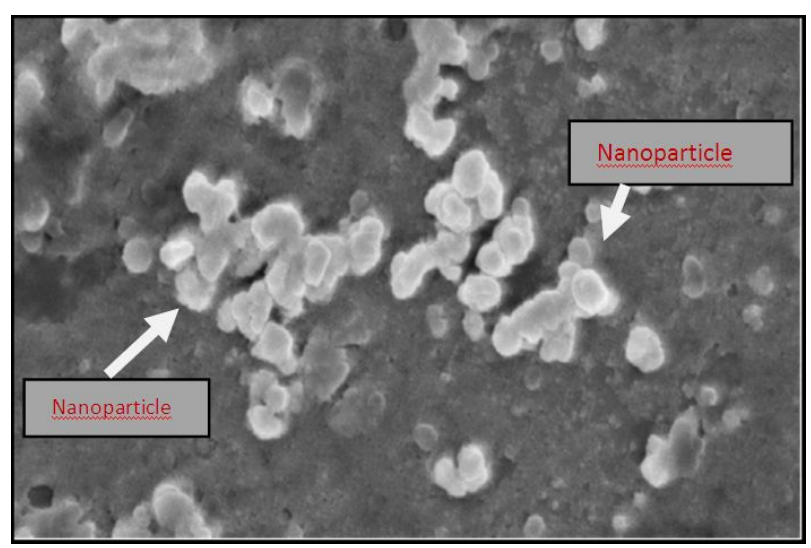

Figure 5: SEM micrograph of synthesized silver nanoparticles. 3.5 Transmission Electron Microscopy (TEM)

TEM is used to directly view the nanoparticles and can be used for direct manual measurement of nanoparticles. While evaluating the 
size by TEM images, it does not include the hydration layer. In DLS, there are measurement of the hydrodynamic diameter which gives the size of the core (nanoparticles) along with any coating material and the solvent layer attached to the particle. Therefore, TEM analysis measures only the size of the nanoparticles. The hydrodynamic diameter is usually greater than the size estimated by TEM. TEM micrograph of the nanoparticles was depicted in Figure 6. The size of the plant mediated silver nanoparticles were found in the range of $2 \mathrm{~nm}-116 \mathrm{~nm}$. The average size of the Neem mediated nanoparticles was found to be $38.54 \pm 2.94 \mathrm{~nm}$.

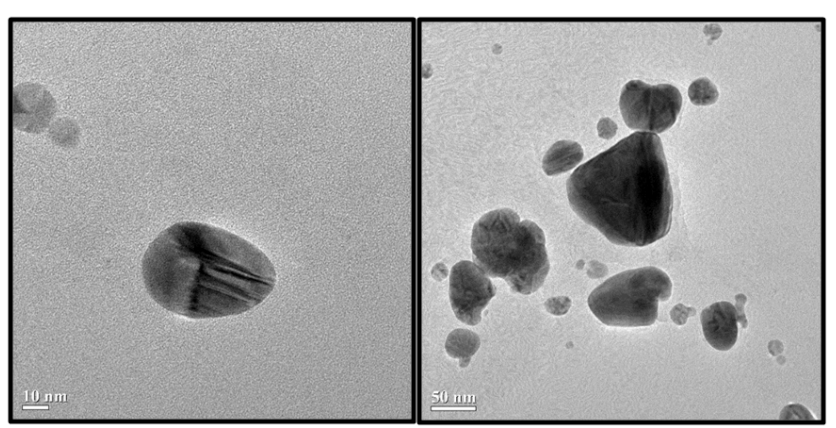

Figure 6: TEM micrographs of synthesized silver nanoparticles at $10 \mathrm{~nm}$ and $50 \mathrm{~nm}$ scale.

\subsection{Antibacterial activities of nanoparticles}

The zone of inhibition (ZOI) of the synthesized nanoparticles against the selected microorganisms are shown in Table 2 . The antibacterial activity of the nanoparticles were evaluated against both gram-positive (Staphylococcus aureus) and gram-negative (Escherichia coli) bacteria by disc diffusion method.

The antibacterial activity of the nanoparticles exhibited sensitive response against the microorganisms at different concentration, viz., 100, 200, 300 and $400 \mu \mathrm{g} / \mathrm{ml}$. Figure 7 displays the images of the ZOI of the nanoparticles against the selected bacteria. The diameter of ZOI was recorded in millimeter using a zone scale. The diameter of the ZOI of Neem mediated AgNPs against $E$. coli ranged from 13 to $19 \mathrm{~mm}$ in different concentration and it was found maximum at $200 \mu \mathrm{g} / \mathrm{ml}$ concentration. The diameter ZOI against Staphylococcus aureus ranged from 12 to $15 \mathrm{~mm}$ and the maximum zone of inhibition was observed at $100 \mu \mathrm{g} / \mathrm{ml}$ concentration. The diameter of zone of inhibition of the standards, viz., ampicillin (10 $\mathrm{mcg}$ ), ciprofloxacin $(5 \mathrm{mcg}$ ) and chloramphenicol (30 mcg) against E. coli were 16, 21 and $22 \mathrm{~mm}$ while against Staphylococcus aureus were 23,12 and $20 \mathrm{~mm}$, respectively. $\mathrm{AgNO}_{3}$ solution $(1 \mathrm{mM})$ also showed antibacterial activity against E. coli and Staphylococcus aureus which was found lesser than the synthesized nanoparticles.

Table 2: Antibacterial potential of the nanoparticles against bacteria

\begin{tabular}{|l|c|c|c|}
\hline \multirow{2}{*}{ Sample } & Concentration $(\boldsymbol{\mu g} / \mathbf{m l})$ & \multicolumn{2}{|c|}{ Zone of inhibition (mm) } \\
\cline { 2 - 4 } & & Escherichia coli & Staphylococcus aureus \\
\hline \multirow{2}{*}{ Neem mediated silver nanoparticles } & 100 & 13 & 15 \\
\cline { 2 - 4 } & 200 & 19 & 13 \\
\cline { 2 - 4 } & 300 & 15 & 12 \\
\cline { 2 - 4 } & 400 & 13 & 23 \\
\hline Ampicillin & $10 \mathrm{mcg}$ & 21 & 12 \\
\hline Ciprofloxacin & $5 \mathrm{mcg}$ & 22 & 20 \\
\hline Chloramphenicol & $30 \mathrm{mcg}$ & 08 & 09 \\
\hline AgNO $_{3}$ & $1 \mathrm{mM}$ & & 16 \\
\hline
\end{tabular}
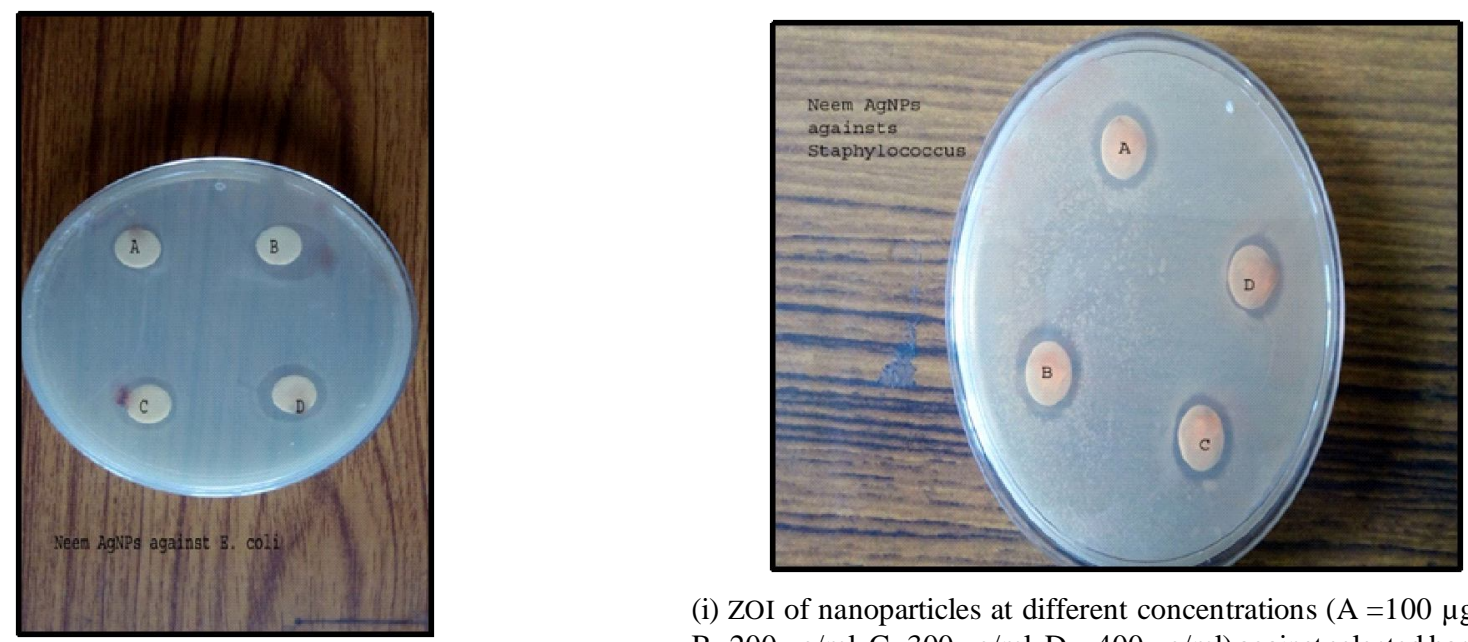

(i) ZOI of nanoparticles at different concentrations (A $=100 \mu \mathrm{g} / \mathrm{ml}$, $\mathrm{B}=200 \mu \mathrm{g} / \mathrm{ml}, \mathrm{C}=300 \mu \mathrm{g} / \mathrm{ml}, \mathrm{D}=400 \mu \mathrm{g} / \mathrm{ml}$ ) against selected bacteria 

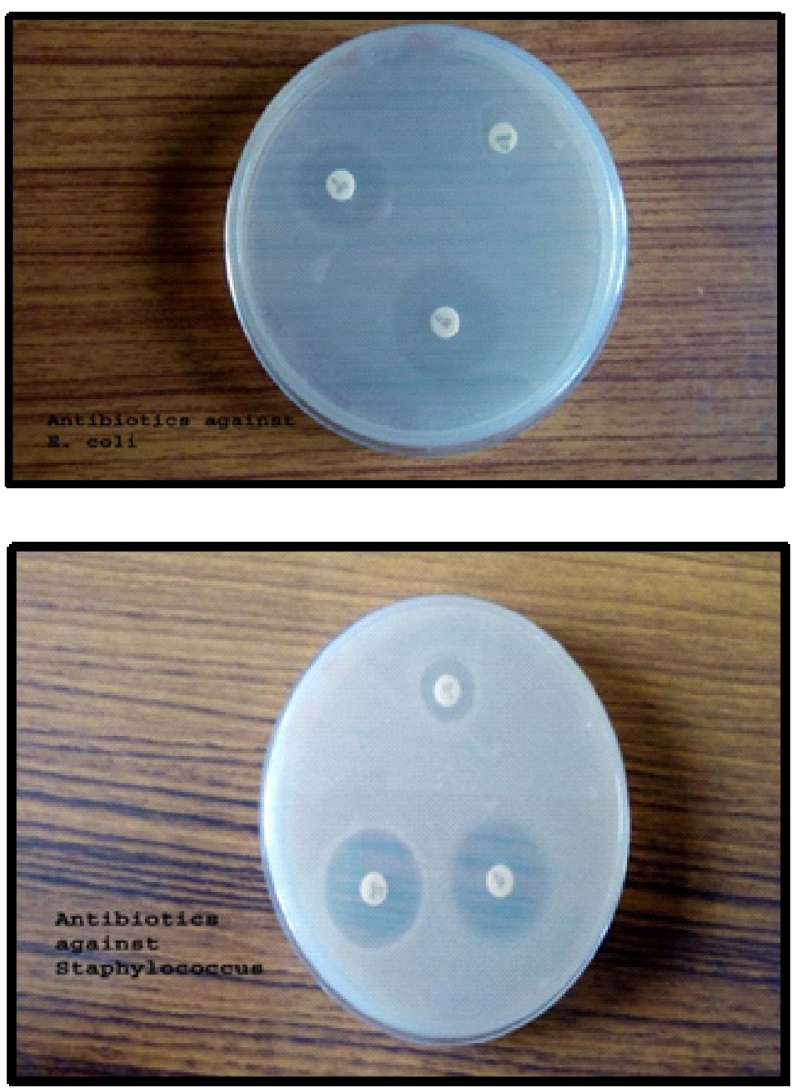

(ii)ZOI of antibiotics (Ampicillin $10 \mathrm{mcg}$, Ciprofloxacin $5 \mathrm{mcg}$, Chloramphenicol $30 \mathrm{mcg}$ ) against selected bacteria.

Figure 7(i-ii): Zone of inhibition (ZOI) of nanoparticles and antibiotics.

\subsection{Antioxidant activityof samples}

The percentage of inhibition of DPPH radical by leaf extracts and plant mediated silver nanoparticles are presented in Table 3. The reactivity of the extracts prepared from A. indica was analyzed with 2, 2-Diphenyl-1-Picryl hydrazyl, a stable free radical which is got reduced by accepting hydrogen or electron from the donor molecule. As DPPH takes up one electron in the presence of a free radical scavenger, the absorption reduces and the resulting discoloration is stechiometrically related to the number of electrons gained (Silva et al., 2005). The inhibition percentage was recorded as Mean \pm SE. The mean per cent inhibition of DPPH radical by aqueous extract and synthesized nanoparticles at $50 \mu \mathrm{g} / \mathrm{ml}$ concentration were observed to be $78.21 \pm 0.12 \%$ and $80.16 \pm$ $0.08 \%$; at $80 \mu \mathrm{g} / \mathrm{ml}$ concentration, it was $80.23 \pm 0.06 \%$ and 85.20 $\pm 0.09 \%$, respectively. At $110 \mu \mathrm{g} / \mathrm{ml}$ concentration, aqueous extract and nanoparticles showed $83.26 \pm 0.18 \%$ and $90.13 \pm 0.06$ $\%$ inhibition against DPPH radical, respectively. The aggregate inhibition percentage of aqueous and silver nanoparticle of Neem leaf extract was $80.57 \pm 0.74 \%$ and $85.16 \pm 1.44 \%$.The inhibition of the standard, butylated hydroxytoluene (BHT) at 50, 80 and $110 \mu \mathrm{g} / \mathrm{ml}$ concentrations were $20.88 \pm 0.10 \%, 38.36 \pm 0.18 \%$ and $56.23 \pm 0.18$, respectively. The aggregate mean value was found to be $38.49 \pm 5.10$.
Table 3: Inhibition percentage against DPPH radical by extracts and synthesized silver nanoparticles.

\begin{tabular}{|l|c|c|c|}
\hline Sample & Type & $\begin{array}{c}\text { Concentration } \\
(\boldsymbol{\mu} / \mathbf{m l})\end{array}$ & Mean \pm SE $(\%)$ \\
\hline \multirow{3}{*}{ A. indica } & Aqueous & 50 & $78.21^{\mathrm{A}} \pm 0.12$ \\
\cline { 2 - 4 } & Extract & 80 & $80.23^{\mathrm{B}} \pm 0.06$ \\
\cline { 2 - 4 } & & 110 & $83.26^{\mathrm{C}} \pm 0.18$ \\
\cline { 2 - 4 } & & Aggregate & $80.57 \pm 0.74$ \\
\cline { 2 - 4 } & Nanoparticles & 50 & $80.16^{\mathrm{B}} \pm 0.08$ \\
\cline { 2 - 4 } & & 80 & $85.20^{\mathrm{D}} \pm 0.09$ \\
\cline { 2 - 4 } & & 110 & $90.13^{\mathrm{E}} \pm 0.06$ \\
\cline { 2 - 4 } & & Aggregate & $85.16 \pm 1.44$ \\
\hline \multirow{4}{*}{ BHT } & Standard & 50 & $20.88^{\mathrm{F}} \pm 0.10$ \\
\cline { 2 - 4 } & & 80 & $38.36^{\mathrm{G}} \pm 0.18$ \\
\cline { 2 - 4 } & & 110 & $56.23^{\mathrm{H}} \pm 0.18$ \\
\cline { 2 - 4 } & & Aggregate & $38.49 \pm 5.10$ \\
\hline
\end{tabular}

BHT=Butylated hydroxy toluene. Different superscript letter represents significantly different $(p<.001)$

\section{Discussion}

The plant mediated AgNPs were observed to change colour from pale greenish yellow to brownish black. AgNPs exhibit dark brown colour depending on the intensity and size of nanoparticles (Krithika et al., 2014).The colour change was due to the surface plasmon resonance phenomenon. The metal nanoparticles like silver have free electrons which gives the surface plasmon resonance absorption band. There is strong interaction of the silver nanoparticles with light due to collective oscillation of the electrons on the metal surface when excited by light at specific wavelengths (Panigrahi, 2013 ; Nath et al.,2007). UV-Vis spectroscopy has been considered as a convenient and preliminary indirect method for characterization of silver nanoparticles based on its surface plasmon resonant property (Kuber and D'souza, 2006). The maximum absorption range of silver nanoparticles in UV-Vis spectrometer is from $300 \mathrm{~nm}$ to 500 nm. (Krithika et al., 2014). The maximum absorption peak of silver nanoparticles of $A$. indica was found to be at $420 \mathrm{~nm}$ wavelength and showed the maximum synthesis of AgNPs. The UV-Vis spectra of the AgNPs are shown in Figure 2. This indicates synthesis of the silver nanoparticles. The reduction of silver ions and subsequent formation of stable nanoparticles were observed within $24 \mathrm{~h}$ of reaction time and, thus making it one of the fastest bioreducing methods to synthesize silver nanoparticles (Kim et al., 2007). In the present study, the findings were in close agreement with Rout et al. (2012) who observed the maximum absorbance peak at 430 $\mathrm{nm}$ for T. chebula mediated nanoparticles. Krithika et al. (2014) observed the maximum absorption peak of AgNPs from T. chebula and Aloe vera at $398 \mathrm{~nm}$ and $410 \mathrm{~nm}$, respectively. Dynamic Light Scattering measures the hydrodynamic radius of the particle. When a dispersed particle passes through a liquid environment, a thin electric dipole layer of the solvent adheres to the surface. This layer affects the motion of the particle in the environment. Thus, the hydrodynamic diameter gives the size of the core along with any coating material and the solvent layer attached to the particle 
as it moves under the influence of Brownian motion. Thus, the diameter of the particle recorded in DLS is greater than the actual size.

Nanoparticles are very small in size for which they are energetically very unstable. So, the particles undergo agglomeration/aggregation to stabilize themselves. Therefore, there were some potential charges on the surface of the nanoparticles which makes them stable (Panigrahi, 2013). The synthesized nanoparticles were found stable. The present findings were found in close agreement with the findings of Panigrahi (2013). The observed report was conformed to the findings of Malapermal et al. (2015). They found zeta potential value of $-25.3 \mathrm{mV}$ for the bimetallic Au-Ag NPs synthesized from the leaf of Ocimum basilicum.

The synthesized nanoparticles using leaf extracts of Neem were found to be almost spherical in shape in SEM. The findings of the present study were found comparable with the results reported by Verma and Mehata (2016) and Malapermal et al. (2015) where the synthesized silver nanoparticles were also found to show spherical in shape. TEM images revealed that majority of the nanoparticles were found spherical in shape while a few was observed as oval in structure. The edges of synthesized nanoparticles were observed lighter than the centre part which may be due to proteins of biomolecules capped with silver nanoparticles (Bindhani and Panigrahi, 2015). The findings of the present study was found comparable to the findings of Bindhani and Panigrahi (2015) and Ahmed et al. (2016). Bindhani and Panigrahi (2015) found the size of 15-45 nm for Tulsi mediated nanoparticles while Ahmed et al. (2016) recorded average size for plant derived nanoparticles at $34 \mathrm{~nm}$.

The exact mechanism by which silver nanoparticles was engaged to cause antimicrobial effect is not clearly known. However, there are different theories on the action of silver nanoparticles on microbes to cause the antimicrobial effect. The inhibitory action of of AgNPs on the growth of microorganisms is due to the attachment of the nanoparticles to the cell membrane followed by penetration inside the bacteria (Kumar et al., 2012). The bacterial cell membrane which contains sulphur containing protein interacts with AgNPs as well as with the phosphorus containing compounds like DNA. The nanoparticles may attack the respiratory chain, cell division and finally leading to cell death of the bacteria. The nanoparticles release silver ions in the bacterial cell which increase the bactericidal activity (Logeswari et al., 2012). Silver nanoparticles also anchor to the bacterial cell wall, penetrate into it and thereby causing structural modification in the cell membrane like the permeability of the cell membrane, followed by death of the bacterial cell. Formation of "pits" on the cell surface and thereby accumulation of the nanoparticles on the cell surface (Sondi and Salopeksondi, 2004). In our present study, gram-negative bacteria was found to show more susceptibility towards AgNPs in comparison to gram-positive bacteria. This may be due to presence of thick layers of peptidogly can which make difficult for penetration of AgNPs in the grampositive bacteria when compared to gram-negative bacteria (Yugandhar et al., 2015). Logeswari et al. (2012) recorded higher zone of inhibition by Ocium tenuiflorum mediated silver nanoparticles against $S$. aureus $(25 \mathrm{~mm})$ and E. coli $(30 \mathrm{~mm})$, respectively in comparison to our present study.
Both aqueous extract and synthesized nanoparticles were found to exhibit good antioxidant activity when compared with standard, BHT. Silver nanoparticles synthesized using extract of $A$. indica showed the maximum inhibition percentage against DPPH radical. Patil et al. (2015) also reported that plant mediated AgNPs showed a remarkable scavenging (\%) activity when compared with standard ascorbic acid and DPPH scavenging activity of AgNPs was found to increase in dose dependent manner which is in good agreement with that of our study. The antioxidant potential of silver nanoparticles could be attributed by functional groups adhere to nanoparticles from leaf extract as they are good source of several antioxidant components such as $\beta$-carotene, gluthione, $\alpha$-tocopherol, ascorbic acids and total phenols and flavonoids (Patil et al., 2015). The present findings corroborated with the findings of Lalitha $e t$ al. (2013) who also recorded that the free radical scavenging activity of the AgNPs using leaf extract of A. indica on DPPH radicals was found to increase with increase in the concentration.

\section{Conclusion}

Leaves extract of $A$. indica is found to be suitable for synthesis of ecofriendly silver nanoparticles.The structure, stability, distribution and morphology of the synthesized nanoparticles were evaluated using UV-visible spectroscopy, DLS, Zeta potential, SEM and TEM. The nanoparticles are found to be almost spherical in shape, uniform distribution and with good stability. The antibacterial study showed that all the selected pathogens were responsive and sensitive to synthesized nanoparticles. Moreover, the nanoparticles showed potential antioxidant activity and are found to be higher than that of plant aqueous extract.

\section{Acknowledgements}

The authors are highly grateful to Assam Agricultural University, Jorhat for all kinds of research facilities throughout the work. The authors are thankful to Institute of Advanced Study in Science and Technology (IASST), Boragaon, Guwahati, Assam, India for allowing to carry out DLS and zeta potential analysis. The authors are also appreciative to the Sophisticated Analytical Instrument Facility (SAIF) in North Eastern Hill University (NEHU), Shillong, Meghalaya, India for TEM analysis of the synthesized nanoparticles.

\section{Conflict of interest}

The authors declare that there are no conflicts of interest relevant to this article.

\section{References}

Ahmad, A. M.; Senapati, S.; Mandal, D.; Khan, M.I.; Kumar, R. and Sastry, M. (2003). Extra cellular biosynthesis of silver nanoparticles using the fungus Fusarium oxysporum. Colloids Surf. B., 28:313-318.

Ahmed, S.; Ahmad, M.; Swami, B. L. and Ikram, S. (2016). A review on plants extract mediated synthesis of silver nanoparticles for antimicrobial applications: A green expertise. J. Adv. Res., 7:17-28.

Ankamwar, B.D.C.; Ahmad, A. and Sastry, M. (2005). Biosynthesis of gold and silver nanoparticles using Emblica officinalis fruit extract, their phase transfer and transmetallation in an organic solution. J. Nanosci. Nanotechnol., 5:1665-1671. 
Bindhani, B.K. and Panigrahi, A.K. (2015). Biosynthesis and characterization of silver nanoparticles by using leaf extracts of Ocimum sanctum L. (Tulsi) and study of its antibacterial activities. J. Nanomed. Nanotechnol., pp:S6-S8.

Cotelle, N.; Bernier, J. L.; Catteau, J. P.; Pommery, J.; Wallet, J. C. and Gaydou, E.M. (1996). Antioxidant properties of hydroxyl flavones. Free Radic. Biol. Med., 20(1):35-43

Evanoff, J.; David, D. and Chumanov, G. (2004). Size-controlled synthesis of nanoparticles measurement of extinction, scattering, and absorption cross sections. J. Phys. Chem. B., 108:13957-13962.

Iravani, S. (2011). Green synthesis of metal nanoparticles using plant. Green Chem., 13:2638-2650.

Kim, J.S.; Kuk, E.; Yu, K. N.; Kim, J. H.; Park, S. J.; Lee, H. J.; Jeong, D. H. and Cho, M.H. (2007). Antimicrobial effect of silver nanoparticles. Nanomed. Nanotechnol. Biol. Med., 3:95-101.

Korbekandi, H.I.S. and Abbasi, S. (2009). Production of nanoparticles using organisms. Crit. Rev. Biotechnol., 29:279-306.

Krithika, K.; Shruthi, C. V. and Geetharamani, D. (2014). Production of silver nanoparticles from Serratia marcescens and its application as antibacterial agent. Scrutiny Int. Res. J. Agri. Plant Biotech. Bio. Pro., 1(5):7-12.

Kruis, F.F.H. and Rellinghaus, B. (2000). Sintering and evaporation characteristics of gas phase synthesis of size-selected $\mathrm{PbS}$ nanoparticles. Mater Sci. Eng. B., 69:329-324.

Kuber, C.B. and D'Souza, S.F. (2006). Extracellular biosynthesis of silver nanoparticles using the fungus Aspergillus fumigates. Colloids Surf B Interface, 47:160-164.

Kumar, K. M.; Sinha, M.; Mandal, B. K.; Ghosh,A. R.; Kumar, K.S. and Reddy P. S. (2012). Green synthesis of silver nanoparticles using Terminalia chebula extract at room temperature and their antimicrobial studies. Spectrochim. Acta. A. Mol. Biomol. Spectrosc., 91:228-233.

Lalitha, A.; Subbaiya, R. and Ponmurugan, P. (2013). Green synthesis of silver nanoparticles from leaf extract Azhadirachta indica and to study its antibacterial and antioxidant property. Int. J. Curr. Microbiol. App. Sci., 2(6):228-235.

Logeswari, P.; Silambarasan, S. and Abraham, J. (2012). Synthesis of silver nanoparticles using plants extract and analysis of their antimicrobial property. J. S. Chem. Soc., 19:311-317.
Magnusson, M.D.;Malm, J.; Bovin, J. and Samuelson, L.(1999). Gold nanoparticles: production, reshaping, and thermal charging. J. Nanopart. Res., 1:243-251.

Malapermal, V.; Mbatha, J. N.; Gengan, R. M. and Anand, K. (2015). Biosynthesis of bimetallic Au-Ag nanoparticles using Ocimum basilicum (L.) with antidiabetic and antimicrobial properties. Adv. Mater. Lett., 6(12):1050-1057.

Merga, G. W.; Lynn, G.; Milosavljevic, B. and Meisel, D. (2007). Redox catalysis on naked silver nanoparticles. J. Phys. Chem. C., 111:12220-12226.

Nath, S. S.; Chakdar, D. and Gope, G. (2007). Synthesis of CdS and ZnS quantum dots and their applications in electronics. Nanotrends., 2(3):20-28.

Panigrahi, T. (2013). Synthesis and characterization of silver nanoparticles using leaf extract of Azadirachta indica. Master Degree Thesis, National Institute of Technology, Rourkela, Orissa, India.

Patil, S.; Rajib, P. and Sivraj, R. (2015). An investigation of antioxidant and cytotoxic properties of green synthesized silver nanoparticles. Indo. Am. J. Pharm. Sci., 2(10):1453-1459.

Rout,Y.; Behera, S.; Ojha, A. K. and Nayak, P. L. (2012). Green synthesis of silver nanoparticles using Ocimum sanctum (Tulashi) and study of their antibacterial and antifungal activities. J. Microbiol. Antimicrob., 4(6):103-109.

Silva, C. G; Herdeiro, R. S.; Mathias, C. J.; Panek,A. D.; Silveira, C. S. and Rodrigues, V. P. (2005). Evaluation of antioxidant activity of Brazilian plants. Pharmacol. Res., 52:229-233.

Sondi, I. and Salopeksondi, B. (2004). Silver nanoparticles as antimicrobial agent: a case study on $E$. coli as a model for Gram-negative bacteria. J. Colloid. Interface. Sci., 275:177-182.

Verma, A. and Mehata, M.S. (2016). Controllable synthesis of silver nanoparticles using Neem leaves and their antimicrobial activity. J. Rad. Res. Appl. Sci., 9(1):109-115.

Wiley, B. S.; Mayers, B. and Xi, Y. (2005). Shape-controlled synthesis of metal nanostructures: the case of silver. Chem. Eur. J., 11:454-463.

Yugandhar, P.; Haribabu, R. and Savithramma, N. (2015). Synthesis, characterization and antimicrobial properties of green-synthesized silver nanoparticles from stem bark extract of Syzygium alternifolium (Wt) Walp. 3 Biotech., 5(6):1031-39. 